\title{
Diet and behavior of the burrowing owl (Athene cunicularia) in Atiquipa, an ecosystem of Lomas in the south of Peru
}

\author{
CÉSAR R. LUQUE-FERNÁNDEZ \\ Instituto de Investigación de Ciencia y Gestión Ambiental, Universidad Nacional de San Agustín de Arequipa (ICIGA-UNSA) \\ Calle San Agustín 108, Cercado, 04001, Arequipa, Perú. Tel./fax.: +51976330247, cluquef@unsa.edu.pe
}

Manuscript received: 18 September 2019. Revision accepted: 12 December 2019

\begin{abstract}
Luque-Fernández CR. 2019. Diet and behavior of the burrowing owl (Athene cunicularia) in Atiquipa, an ecosystem of Lomas in the south of Peru. Biodiversitas 20:137-143. The study of trophic and behavioral habits is a fundamental aspect in the knowledge of the natural history of species, especially for those that present a wide range of distribution and that have to adapt to the habitats and available resources that can find to survive. The diet and behavior of Athene cunicularia were studied in a peculiar ecosystem such as the lomas formation, on the arid coast of southern Peru. The analysis of regurgitated pellets from a family group of Athene cunicularia was used and complemented with the monitoring of behavior through the use of trap cameras and direct observations. The results show that the diet during the months of study was based on a high proportion of invertebrate beetles (Tenebrionidae) and scorpions, also finding remains of vertebrates, including rodents, birds and highlighting the presence of a species of marsupial mouse. On the study of behavior, marked and recurrent activities are established during the day for this species, where grooming sessions are frequently reported, as well as interaction with a possible predator of this owl species. These results contribute to the understanding of the trophic relationship and its role in the studied lomas ecosystem, which is added to the importance of this species in the conservation of diversity in desert ecosystems.
\end{abstract}

Keywords: Beetles, ecology, marsupial, raptors, tenebrionidae, camera trap

\section{INTRODUCTION}

The study of trophic and behavioral habits that may occur within and between different species are fundamental aspects of the study of their natural history, where in the case of raptors the study of diet through pellet analysis is presented as a tool to know the relationships with their prey and the variability that these may present in time and space, as well as adaptive processes of change that may occur in these variables (Orihuela-Torres et al 2018), which correlates with the effectiveness that species use habitat and behavioral responses (Pairo et al. 2017).

The Burrowing Owl (Athene cunicularia Molina, 1782), is a strigiform bird characterized by occupying and nesting in underground rodent burrows, also presenting mainly diurnal and crepuscular habits (Haug et al. 1993). It is widely distributed in the Americas, from Canada to southern Argentina, in diverse environments such as grasslands, meadows, steppes and open hills, with the presence of low-growth shrubs that allow it to increase its visibility, as well as in arid areas (Haug et al. 1993; König and Weick 2008; Holt et al. 2019). However, despite its wide distribution and its classification as "Last Concern" on a global scale (IUCN), some populations such as in North America are suffering significant declines, becoming considered a species of national priority in the United States (Holroyd et al. 2001). This is a consequence of numerous factors, including habitat loss, reduced availability of burrows and food (Aradis and Carpaneto 2001).
Athene cunicularia have a generalist food habit, feeding on a wide range of prey that includes arthropods such as insects and arachnids, and vertebrates like small mammals, birds and reptiles, invertebrates being predominant (Nabte et al. 2004; Vieira and Teixeira 2008; Roque-Vazquez et al. 2017). Although there are numerous works related to the diet of this species in North America and semi-arid habitats in Latin America (e.g., Tommaso et al. 2009; Carevic 2011; Limonggi 2014), little is known about their trophic habits of the species in Peru, and more specifically in the ecosystem of Lomas (Medina et al. 2013) and even less of their behavior incorporating the use of trap cameras (Herse 2016; Riding and Belthoff 2018).

The studies of diet and behavior of this species in lomas ecosystems take importance over the conditions under which it survives since it presents a great dependence on the variation of local climatic conditions and the response of vegetation, in addition to species such as these represent an important factor in the conservation of diversity in lomas ecosystems. (Rengifo-Faiffer and Arana 2019) on the other hand, it takes on importance since the population in this lomas is in recovery, since it suffered a great reduction due to the use of its blood for medicinal rituals.

The aim of this work was to perform an evaluation about the diet and behavior of Athene cunicularia in a peculiar ecosystem such as the coastal lomas in Atiquipa, for being a natural plant formation settled in the Peruvian desert in southern Peru, which depends on the fog for subsistence of this ecosystem. Also, it is intended to provide information on these variables through the analysis 
of regurgitated pellets and the use of trap cameras as a tool for the analysis of animal behavior that is increasingly being used.

\section{MATERIALS AND METHODS}

\section{Study area}

The study was conducted in an ecosystem of coastal lomas in the district of Atiquipa (province of Caraveli, Arequipa) $\left(20^{\circ} 24^{\prime} \mathrm{S}, 69^{\circ} 44^{\prime} \mathrm{W}\right)$, where the formation of lomas area denominated as peculiar ecosystems since they are presented as scarce oases of vegetation along the arid coast of the Chilean-Peruvian desert. In the case of Atiquipa represents the largest area (22800 ha) for this type formation throughout Peru (Canziani and Mujica 1997; Villegas et al. 2017). These lomas extend between 100 and 1200 meters of altitude, with presence of vegetation herbaceous, shrub and an important extension of forest of trees of Tara (Caesalpinia spinosa). In these locations two distinct climatic seasons are distinguished: dry (DecemberMay) and humid (June-November). In the latter, large fog events occur, which generates a type of drizzle called "horizontal rain" that affects the dynamics of vegetation (Sotomayor and Jiménez 2008).

\section{Procedures}

Obtaining diet information

The fieldwork was conducted between October and December 2013 (wet season). The diet of the species was assessed by analyzing regurgitated pellets collected around an active burrow of Athene cunicularia located at $360 \mathrm{~m}$ asl $\left(15^{\circ} 47^{\prime} 33.58\right.$ "S, $\left.74^{\circ} 22^{\prime} 20.34^{\prime \prime} \mathrm{O}\right)$, in the creek called "Tambo". This site was selected for this evaluation because individuals were frequently sighted in this area, as well as because of the low human disturbance in the area and the lack of accessibility to the site. The burrow was characterized by being between two large rocks, surrounded by low shrub vegetation and a large proportion of bare soil. The collection of pellets was made every 15 days, considering a radius of 2 meters from the evaluated burrow and considering only those that were compact, discarding the disintegrated. These were measured in the field and subsequently saved and labeled for processing.

For the determination of the prey items found in the pellets, the following structures were considered in the count: craniomandibular fragments like skulls, jaws and bones (mammals, birds, and reptiles), heads (beetles, ants), legs and heads (orthoptera), only stingers (scorpions) (Tommaso et al. 2009). In the case of the bones (femur, ribs, tarsus), these remains were considered to belong to a single individual, when the skull was not in the pellets. Subsequently, the frequency of occurrence $(F)$ of the prey items was calculated using the methodology of OrihuelaTorres et al. (2018): $\mathrm{F}=\mathrm{Ni} / \mathrm{Nt}$ x 100 ( Ni=number of individuals of the species / $\mathrm{Nt}=$ total number of prey) where the period of study was considered as total sample.

\section{Study of behavior and interactions}

Two methodologies were used to study the behavior of Athene cunicularia, where two trap cameras (8mpx, ScoutGuard SG560VB) were used, one installed between 1 and 2 meters from the entrance of the evaluated burrow and the second (optional), approximately 10 meters from the burrow to have a panoramic view of the area. The configuration of the cameras varied between photographs, captured by activation of the motion sensor, and also short videos (10 seconds). The information of the installed cameras was collected every 7 days, which was the effective time of operation of these based on the storage and duration of the batteries.

For the initial processing of the images and videos obtained, the following behaviors were considered: time of entry and exit of the burrow, time and type of activity developed and the presence of other animal species. Likewise, the information obtained was complemented with 60-minute sighting sessions that varied between 8:00 and 17: 00 hours, between the evaluation months, at least two sessions per week were included (Iannacone et al. 2012), which was done with 10x50 binoculars at an approximate distance of $80 \mathrm{~m}$ from the burrow, behind a rock facing the burrow evaluated.

\section{RESULTS AND DISCUSSION}

\section{Diet}

The burrow evaluated was formed by a family group of 3 individuals of Athene cunicularia. In total 25 pellets were collected, these pellets were mostly black and dark grey in color, which can be attributed to the content of beetles and mammals respectively. These had an average weight of 1.4 \pm 0.6 g. with dimensions of length $33.5 \pm 7.2 \mathrm{~mm}$ and width $15.8 \pm 0.7 \mathrm{~mm}$ whose sizes are similar to those reported by Orihuela-Torres et al. (2018) in Ecuador, but larger than those reported in "Cerro Campana" in Trujillo (Peru) with $27.83 \pm 0.6$ y de $13.28 \pm 0.1$ (Medina et al. 2013), which is also mentioned as an important attribute to report as it could serve to differentiate species or maybe subspecies of Strigiformes in an area (Roque-Vásquez 2017), in this case, it could correspond to the subspecies nanodes for its distribution (Holt et al. 2019).

For the diet, 2378 items were identified, corresponding to eight types of prey (Table 1), this is a smaller number compared to other investigations (Medina et al. 2013; Roque-Vazques et al. 2017) although it would be associated with the short time of this study. The most consumed prey items were invertebrates (beetles and scorpions) similar to that found in other research and in a variety of habitats evaluated (Nabte 2004; Moulton et al. 2005; Vieira and Texeira 2008; Tommaso et al. 2009; Medina et al. 2013; Cavalli et al. 2014; Cadena-Ortiz et al. 2016; Orihuela-Torres et al. 2018; Ruiz et al. 2019). In Roque-Vázquez et al. (2017) mentions that this preference for invertebrates is maintained in dry and humid seasons in xerophytic environments such as the Atiquipa lomas, which is supported by the fact that invertebrates such as 
Coleoptera, being terrestrial insects, can be captured more easily and with less effort (Ruiz et al. 2019).

Remains of vertebrates were also found in smaller amounts (e.g., birds, Didhelphdae and Cricetidae) highlighting bones of unidentified birds, not finding skulls or beaks, similar to those found by Orihuela-Torres et al. (2018), who also mentions that these remains were not found within the pellets, but can be found around the entrance of the nests or burrows, Medina et al. (2013) reports that $A$. cunicularia can consume birds such as Zonotrichia capensis and Columbina cruziana which are also common in these lomas (Figure 1).

Related to the consumption of mammals, a single individual represents a large contribution in biomass much higher than that provided by the invertebrates (Herse 2016), for this research it is reported as a new item within the diet of A. cunicularia to the "fat-tailed opossum mouse" (Thylamis sp.), which had not been previously reported. This mammal is restricted in southern Peru and the identity of the species is still unknown because it has not been scientifically described (Pacheco et al. 2009). Additionally, the presence of plant matter is reported, including seeds of a Cactaceae (Haageocereus spp.) and leaf remains of a species of mallows (Orihuela-Torres et al. 2018), which can be incorporated indirectly when consuming prey.

Within the diet of A. cunicularia, $80 \%$ of beetles correspond to the family Tenebrionidae, similar to that found by other research (Roque-Vasquez et al. 2017; Orihuela-Torres et al. 2018; Valladares et al. 2018; Ruiz et al. 2019), which shows the preference for this taxon even in different environments, therefore, the lomas of Atiquipa, act as a resource available throughout the year and easy to obtain, it was also observed that the consumption of another beetle (Scarabacidae) only occurred during the month of December, the same happened with the scorpions and ants that were found in greater quantity, for the other items the incorporation to the diet of A. cunicularia was indistinct in the months.

The increase in prey availability is due to in December the vegetation in the lomas is reaching its peak, where the plant diversity is increased (Sotomayor and Jiménez; 2008) as well as the presence of other insects, and the abundance of mollusks terrestrial (gastropods), which are also occasionally incorporated (Orihuela-Torres et al. 2018; Medina et al. 2013; Cadena-Ortiz et al. 2016; Ruiz et al. 2019). This may be related to the fact that the variation of food resources in the lomas could be conditioned between the dry and wet seasons, as well as the types of habitats present, which would reflect in the diet of species that use these resources.

Athene cunicularia has a diet that depends on the availability of resources (Kavanangh 2002, Tomasso et al. 2009), complementing the hypothesis that species such as this one, which has as characteristics wide ranges of distribution and lives in a variety of habitats, would have a great plasticity on the type of food that can be incorporated into their diet (Rocha et al. 2011). This food plasticity is an important factor in bird's raptors, due to its role in the control of pest populations, such as insects and mammals (Carevic 2011).

\section{Behavior}

A total of 5199 photographs (27 days/camera) and 1.8 hours of video were collected. Through the analysis, 4 general types of behavioral activities for A. cunicularia were established: vigilance, return or rest, grooming and feeding. Establishing that the Burrowing Owl, during the assessment months, performs long grooming sessions combined with vigilance at different times of day (Figure 2 ), with grooming sessions of 20 to 40 minutes, sometimes individually or between individuals, which was previously reported (Haug et al. 1993; Limonggi 2014).

These grooming sessions were performed when they left burrowing (7-12 hours) and upon returning (16-17 hours), which would be due to a strategy to eliminate the ectoparasites taking advantage of the hours of higher temperature (Herse 2016), it has also been reported that they perform dust baths for this purpose, which were not recorded in this study. In the case of the grooming in the afternoon would be done to order the feathers and keep the heat at night.

Between 12 and 16 hours no individuals are recorded in the trap cameras or in the observations made in the field. This interval was used to searching food, which differs with the normal behavior associated with this species, where night habits are attributed between 20 to 6 hours (Haug and Oliphatn 1990), although in areas of Chile and Venezuela they tend to be a more diurnal and crepuscular than nocturnal bird (Martinez and Gonzales 2004; Limonggi 2014; Valladares et al. 2018). In addition, to the same species in other locations, it is mentioned that the burrowing owl can travel between $200 \mathrm{~m}$ and $2 \mathrm{~km}$ away from the nest to feed, being able to present exceptional events of longer distances in seasons of reproductive events. Finally, upon returning and from 21 hours, individuals are protected in the burrow and no activity of the species is recorded during the night or early morning.

Table 1. Prey item in Athene cunicularia pellets between October and December 2013 and their frequency of occurrence

\begin{tabular}{lcc}
\hline Prey item & Items number & Frequency (\%) \\
\hline $\begin{array}{l}\text { Coleopterans } \\
\text { Tenebrionidae }\end{array}$ & 1896 & 79.73 \\
$\quad \begin{array}{l}\text { Scarabaeidae } \\
\text { Ants }\end{array}$ & 150 & 6.31 \\
$\quad$ Formicidae & & \\
$\begin{array}{l}\text { Scorpion } \\
\quad \text { Bothriuridae }\end{array}$ & 86 & 3.62 \\
Total invertebrates & 230 & \\
$\quad$ Mammals & 2362 & 9.67 \\
$\quad$ Cricetidae & & 99.33 \\
$\quad$ Didelphidae & & \\
Birds & 8 & 0.34 \\
$\quad$ Unidentified birds bones & 3 & 0.13 \\
Total vertebrates & 4 & 0.17 \\
$\quad$ Others & 15 & 0.63 \\
$\quad$ Gastropoda & & \\
Total & & 0.04 \\
\hline
\end{tabular}




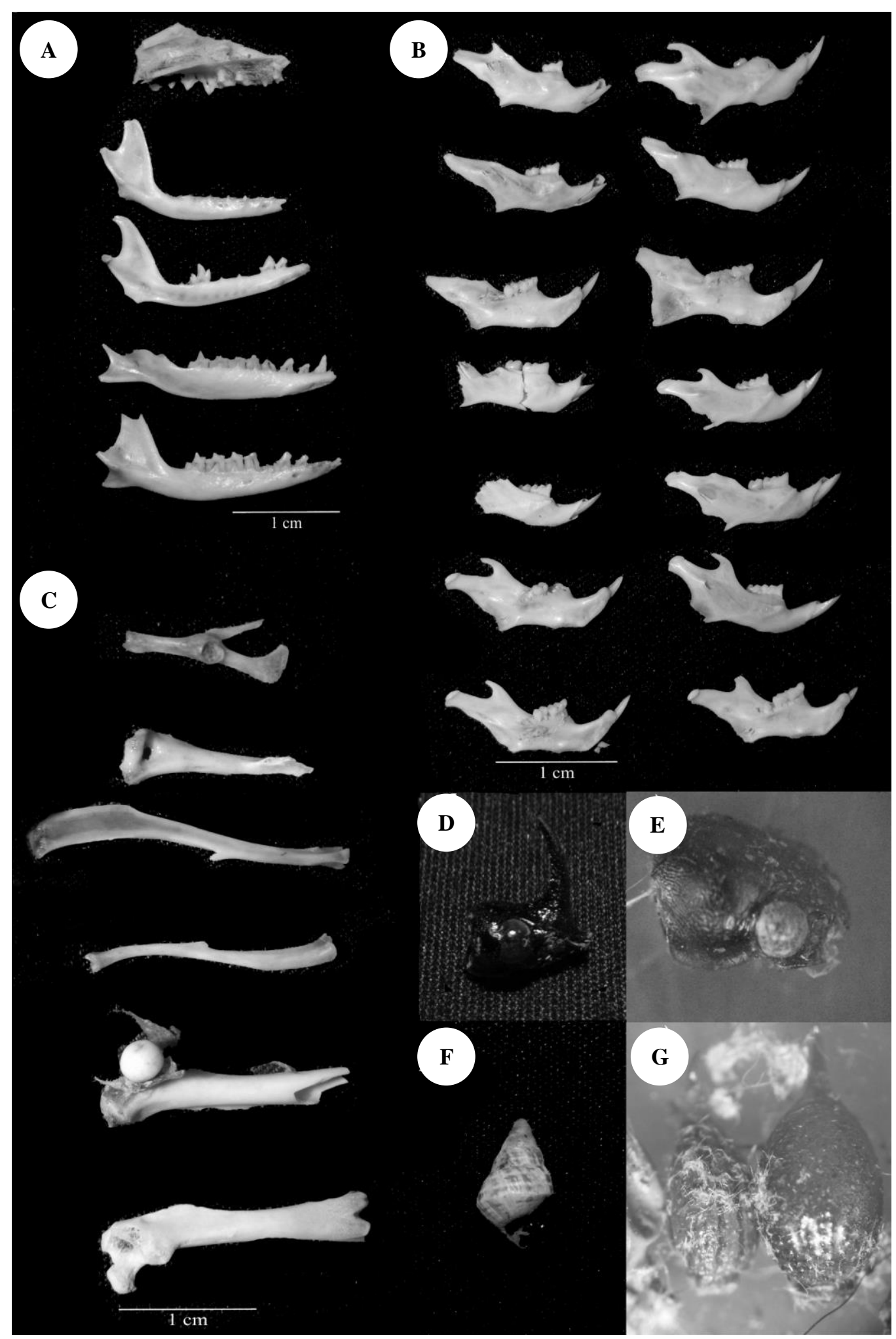

Figure 1. Prey items found during the evaluation: A. Jaws of Didelphidae (Thylamys spp.), B. Jaws of Cricetidae, C. Unidentified birds and mammals bones, D. Head of Scarabidae, E. Head of Tenebrionidae, F. Gastropod, G Bothriuridae sting

Additionally, within the interactions that were recorded by camera traps, it has the registration of two mammals associated to burrow evaluated, these were a "big-eared mouse", possibly the genus Phyllotis spp., which seek seeds in the material of pellets disintegrated, and take advantage of the rocks to be able to mobilize and avoid predators (York et al. 2002). 


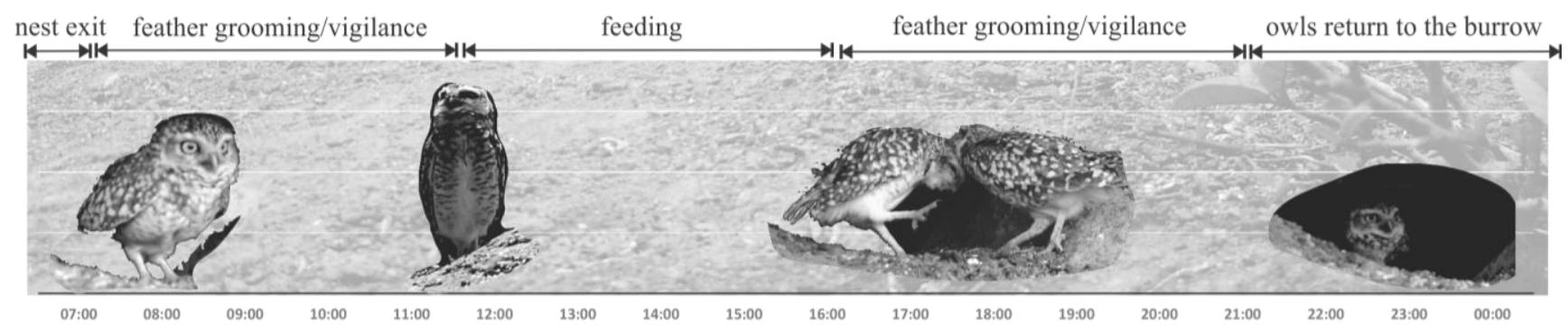

Figure 2. Behavior established for Athene cunicularia between October and December 2013 in the Atiquipa lomas, Perú

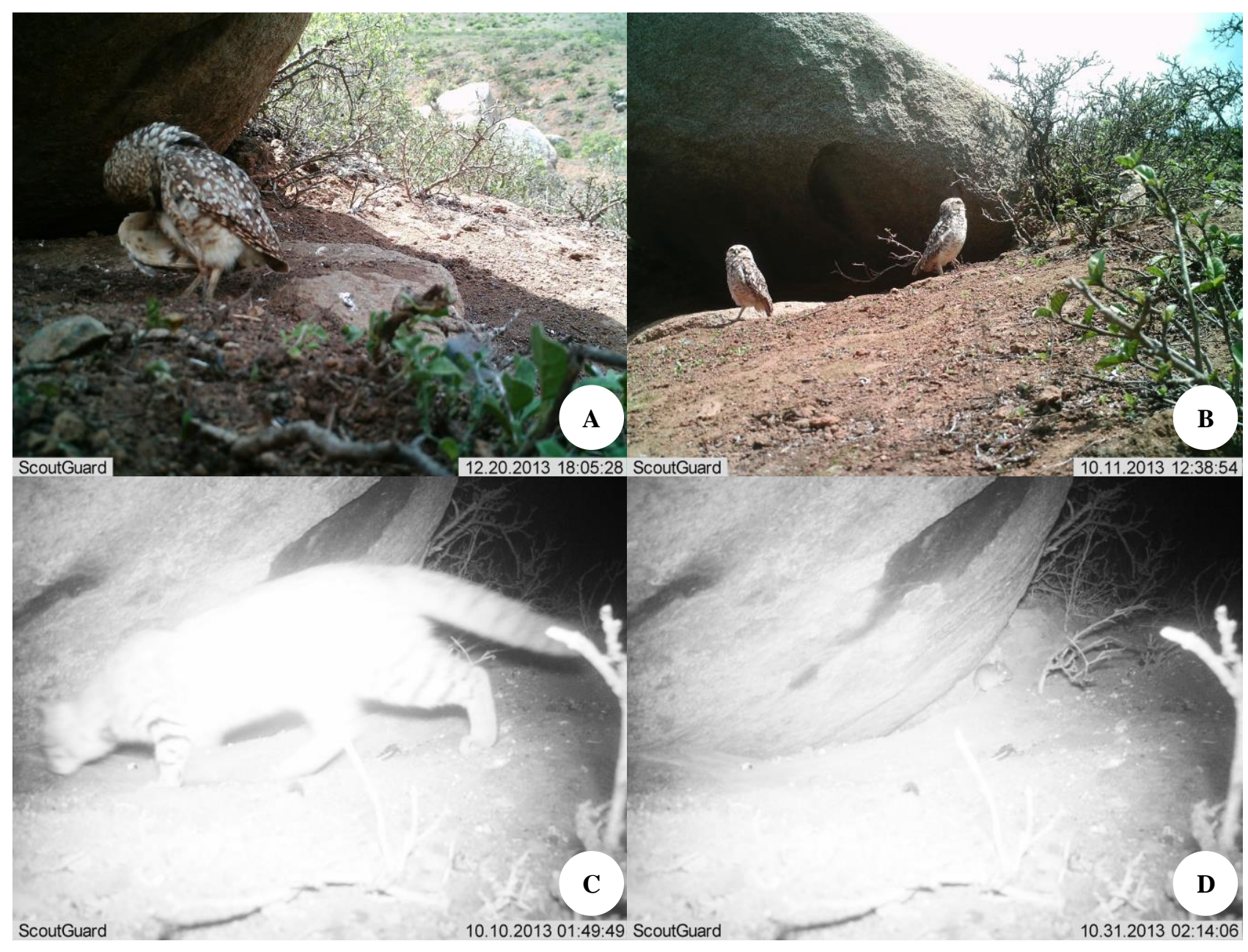

Figure 3. Photos of the evaluation with trap cameras in Atiquipa lomas: A. Periods of grooming, B. Family group evaluated, C. Leopardus colocolo predator visiting the burrow; D. Big-eared mouse at the entrance of the burrow

The second record corresponded to a feline (Leopardus colocolo), which is a rare species to register in this lomas, which would form one of the predators of the burrowing owl. It is known diet of this feline that includes "vizcachas" (Lagidium peruanum) wich is also present in the area of lomas, and sometimes incorporates some birds such as ducks and common gallinule (Fajardo 2014). The big-eared mouse was recorded frequently, and always between the hours 22 hours and 5 hours, while Leopardus colocolo was registered only twice at dawn, around 2 hours (Figure 3).

The eating habits of Athene cunicularia, in an ecosystem of coastal lomas during the period de studio (wet season), show the dominance of consumption of invertebrates (Coleoptera) with the addition of some vertebrates especially rodents and marsupials, as well as a variation of the available resource and the response of the selection of prey by the Burrowing Owl; about their behavior, the use of trap cameras did not present alteration 
to the individuals studied like Garcia and Conway (2009), and it is concluded that $A$. cunicularia has established daytime activity habits, highlighting large periods of feather grooming and an established time range for feeding.

The understanding and knowledge of the diet and behavior of the species studied is presented as a tool to propose conservation strategies for the population of this raptor (Ruiz et al. 2019), which is capable of naturally controlling the populations of other species (pests) and also contribute to understanding their trophic relationship and role in ecosystems such as the one studied.

The results obtained in this investigation are accurate, since they correspond to the monitoring of a family group of A. cunicularia, in a single location of this lomas formation, where the methodological limitation was established by the number of trap cameras available to follow the behavior, as well as the permanence of the family group associated to the burrow evaluated.

\section{ACKNOWLEDGEMENTS}

Thanks to the peasant community of Atiquipa and its inhabitants, as well as Simon Tweed who provided the trap cameras and Anthony Pauca for their support in the field assessments, also to thank Johana del Pilar y Angie Montenegro for her valuable review and comments on the manuscript.

\section{REFERENCES}

Aradis A, Carpaneto G. 2001 A survey of raptors on Rhodes: an example of human impacts on raptor abundance and distribution. J Raptor Res Rep 35 (1): 70-71.

Cadena-Ortiz H, Garzón C, Villamarín-Cortéz S, Pozo-Zamora G.M Echeverría-Vaca G, Yánez J, Brito J. 2016. Diet of the Burrowing Owl Athene cunicularia, in two locations of the inter-Andean valley Ecuador. Revista Brasileira de Ornitología 24 (2): 122-128. [Spanish]

Canziani J, Mujica E. 1997. Atiquipa: un caso prehispánico de manejo sustentable en ecología de Lomas. Páginas 503-526. En: E. González, B. Revesz, A. Tapia (eds.) Perú: El problema agrario en debate Seminario Permanente e Investigación Agraria VI. Lima-Perú. [Spanish]

Carevic FS. 2011. Rol del pequén (Athene cunicularia) como controlador biológico mediante el análisis de sus hábitos alimentarios en la Provincia de Iquique, norte de Chile IDESIA. DOI: 10.4067/S0718 34292011000100003. [Spanish]

Cavalli M, Baladrón AV, Isacch JP, Martínez G, Bó MS. 2014. Prey selection and food habits of breeding Burrowing owls (Athene cunicularia) in natural and modified habitats of Argentine Pampas. Emu 114 (2): 184-188. DOI: 10.1071/MU13040

Fajardo U. 2014. Ecología trófica de Leopardos colocolo (carnívora: felidae) en la reserva nacional de Junín y alrededores. [Thesis].Universidad Nacional Mayor de San Marcos, Lima, Peru. [Spanish]

Garcia V, Conway C. 2009. Use of video probe does not affect burrowing owl reproductive parameters or return rates. J Wildlife Manag 73 (1): 154-157. DOI: $10.2193 / 2008-112$

Haug E, Oliphant L. 1990. Movements, activity patterns, and habitat use of Burrowing Owls in Saskatchewan, Canadá. J Wildlife Manag 54 (1): 27-35.

Haug E, Millsap B, Martell S. 1993. Burrowing Owl (Speotyto cunicularia). In: Poole A, Gill F (eds.). The Birds of North America, No. 61. The Academy of Natural Sciences, Philadelphia, PA, and the American Ornithologists' Union. Washington, D.C.
Herse M. 2016. Diet and behavior of extralimital western burrowing owls (Athene cunicularia hypogea) in tallgrass prairie. Southwestern Naturalist 61 (4): 341-348

Holroyd G.L, Rodríguez-Estrella R, Sheffield S.R. 2001. Conservation of the burrowing owl in western North America: issues, challenges, and recommendations. J Raptor Res 35 (4): 399-407.

Holt DW, Berkley R, Deppe C, Enríquez Rocha P et al. 2019. Burrowing Owl (Athene cunicularia). In: del Hoyo J, Elliott A, Sargatal J, Christie DA, de Juana E. (eds.). Handbook of the Birds of the World Alive. Lynx Editions, Barcelona.

Iannacone J, Villegas W, Calderón M, Huamán J, Silva-Santiesteban M, Alvariño L. 2012. Patrones de comportamiento diurno de Huerequeque Burhinus superciliaris en hábitats modificados de la costa central del Perú. Acta Zoológica Mexicana, 28 (3): 507-524. [Spanish]

Kavanagh RP. 2002. Comparative diets of the Powerful Owl (Ninox strenua), Sooty Owl (Tyto tenebricosa) and Masked Owl (Tyto novaehollandiae) in southeastern Australia. In: Newton I, Kavanagh R, Olsen J, Taylor I (eds.). Ecology and Conservation of Owls. CSIRO Publishing, Collingwood, Australia.

König C, Weick F. 2008. Owls of the World. 2nd ed. Christopher Helm, London

Limonggi, T. 2014. Caracterización de la dieta y comportamiento alimentario de Athene cunicularia (Mochuelo de hoyo) en el Hato Masaguaral [Thesis].Universidad de Carabobo. [Spanish]

Martínez D, González G. 2004. Las Aves de Chile, Nueva Guía de Campo. Ediciones del Naturalista. Santiago, Chile. [Spanish]

Medina CA, Zelada W, Pollack J, Huamán E, Gómez A. 2013. Dieta de la lechuza de los arenales, Athene cunicularia, en Trujillo y en el Cerro Campana, La Libertad (Perú). Rebiol 33 (2): 99-106. [Spanish]

Moulton CE, Brady RS, Belthoff JR. 2005. A comparison of breeding season food habits of Burrowing Owls nesting in agricultural and nonagricultural habitat in Idaho. J Raptor Res 39 (4): 429-438.

Nabte MJ. 2004. Dieta de Athene cunicularia (Aves: Strigiformes) en el nordeste de la provincia del Chubut, Argentina. Mastozoología. Neotropical 11 (2): 252-253. [Spanish]

Pacheco V, Cadenillas R, Salas E, Tello C, Zeballos H. 2009. Diversidad y endemismo de los mamíferos del Perú. Revista Peruana de Biologia 16 (1): 005-032

Pairo PE, Leveau LM, Belloco MI. 2017. Selección del hábitat de nidificación de la lechuza vizcachera (Athene cunicularia) en agroecosistemas de la Pampa Ondulada. Ecología Austral 27: 375384. DOI: 10.25260/EA.17.27.3.0.465. [Spanish]

Orihuela-Torres A, Ordóñez-Delgado L, Brito J, López F, Mazón M, Freile MF. 2018. Ecología trófica del búho terrestre Athene cunicularia punensis en el archipiélago de Jambelí, provincia de El Oro, suroeste de Ecuador. Revista Peruana de Biología 25 (2): 123130. DOI: 10.15381/rpb.v25i2.13376. [Spanish]

Rengifo-Faiffer MC, Arana C. 2019. Fossorial birds help shape the plant community of a Peruvian desert. J Arid Environ. 169: 29-44. DOI: 10.1016/j.jaridenv.2019.104011

Riding C, Belthoff JR. 2018. Breeding dispersal by Burrowing Owls (Athene cunicularia) in Idaho. J Raptor Res 52 ( 2): 143-157. DOI: 10.3356/JRR-17-17.1

Rocha RG, Ferreira E, Fonseca LR, Costa LP. 2011. Small mammals in the diet of Barn owls, Tyto alba (Aves: Strigiformes) along the midAraguala River in central Brazil. Zoología 28 (6): 709-716. DOI: 10.1590/S1984-46702011000600003

Roque-Vásquez G, Muñoz-Gil J, Marin-Espinosa G. 2017. Seasonal variation in diet of burrowing owl (Athene cunicularia) in a xeric habitat from northeastern Venezuela. The Biologist (Lima) 15 (2): 311-327

Ruiz G, Olalla A, Guzmán A, González JI. 2019. Diet and prey delivery of Burrowing Owls (Athene cunicularia hypugaea) during the breeding season in the Chihuahuan desert, Mexico. J Raptor Res 53 (1), 75-83. DOI: $10.3356 /$ JRR-17-90

Sotomayor D, Jimenez P. 2008. Condiciones meteorológicas y dinámica vegetal del ecosistema costero lomas de Atiquipa (Caravelí-Arequipa) en el sur del Perú. Ecología Aplicada 7: 1-8. DOI: 10.21704/rea.v7i1 2.353. [Spanish]

Tommaso DC, Callicó RG, Teta P, Pereira JA. 2009. Dieta de la Lechucita Vizcachera (Athene cunicularia) en dos áreas con diferente uso de la tierra en el centro-sur de la provincia de La Pampa, Argentina. Hornero 24 (2): 87-93 
Valladares P, Urrutia N, Álvarez N, Alvarado S. 2018. Comparación de la dieta del pequén (Athene cunicularia) a nivel intra e interespecífico en el desierto de Atacama, Chile. Interciencia 43 (2): 93-97. [Spanish]

Vieira LA, Teixeira LR. 2008. Diet of Athene cunicularia (Molina, 1782) from a sandy coastal plain in southeast Brazil. Boletim do Museu de Biologia Mello Leitão 23: 5-14.
Villegas L, Caballero KC, Luque-Fernández CR. 2017. Fauna Silvestre de las Lomas de Atiquipa. Universidad Nacional de San Agustin de Arequipa, Peru. [Spanish]

York M, Rosenberg DK, Sturm KK. 2002. Diet and food-niche breadth of Burrowing Owls (Athene cunicularia) in the Imperial Valley, California. W. North Am Nat 62: 280-287. 